\title{
Neonatal Macrosomia Is an Independent Risk Factor for Adult Metabolic Syndrome
}

\author{
Gregory M. Hermann Lindsay M. Dallas Sarah E. Haskell Robert D. Roghair \\ Department of Pediatrics, University of lowa, Carver College of Medicine, lowa City, lowa, USA
}

\section{Key Words}

Diabetes, type $2 \cdot$ Glucose tolerance $\cdot$ Hypertension .

Macrosomia

\begin{abstract}
Background: Weight in infancy correlates with risk of type 2 diabetes, hypertension, and obesity in adulthood. Clinical observations have been confounded by obesity-prone genotypes and obesity-linked lifestyles. Objectives: To define the effects of isolated neonatal macrosomia in isogenic animals, we compared macrosomic and control C57Bl6 mice co-fostered by healthy dams receiving standard laboratory feed. Methods: Naturally occurring neonatal macrosomia was identified by a gender-specific weanling weight above the 90th percentile for the colony. Macrosomic and control mice were phenotyped in adulthood by exercise wheel, tail cuff and intraperitoneal insulin or glucose challenge. $\boldsymbol{R e}$ sults: Compared to control males, adult males with a history of neonatal macrosomia had significantly increased body weight, reduced voluntary activity, insulin resistance, fasting hyperinsulinemia, and impaired glucose tolerance. In contrast, adult females with neonatal macrosomia had no significant alteration in body weight or endocrine phenotypes, but did have higher blood pressures and lower heart rates than control females. After these baseline studies, all mice were switched to a hypercaloric, high fat diet $(5 \mathrm{kcal} / \mathrm{g}, 45 \%$
\end{abstract}

of energy as fat). Twenty weeks later, male mice had impaired glucose tolerance and insulin resistance, independent of their weanling weight classification. While on high fat feeds, macrosomic males maintained a significantly higher body weight than control males. Conclusions: We conclude that (1) in our murine model, neonatal macrosomia is an independent risk factor of adult metabolic syndrome, and (2) neonatal macrosomia accentuates the sexually dimorphic predisposition of C57Bl6 male mice towards glucose intolerance and C57BI6 female mice towards hypertension.

Copyright $\odot 2010$ S. Karger AG, Basel

\section{Introduction}

Macrosomic infants are at an increased risk of type 2 diabetes mellitus, hypertension, and obesity in adulthood [1-4]. While epidemiological studies have shown neonatal macrosomia is associated with adverse effects on adult metabolic health, these observations are confounded by obesity-prone genotypes, obesity-linked lifestyles and maternal comorbidities [1]. Animal models have been developed to clarify these associations.

Sources of Funding: National Institutes of Health, HD050359.

\begin{tabular}{ll}
\hline KARGER & ( 2010 S. Karger AG, Basel \\
Fax +41613061234 & \\
$\begin{array}{l}\text { E-Mail karger@karger.ch } \\
\text { www.karger.com }\end{array}$ & $\begin{array}{l}\text { Accessible online at: } \\
\text { www.karger.com/neo }\end{array}$
\end{tabular}

Robert D. Roghair, MD

Department of Pediatrics, 1270 CBRB, University of Iowa Carver College of Medicine 285 Newton Road

Iowa City, IA 52242 (USA)

Tel. +1 319335 9895, Fax +1 319356 4685, E-Mail robert-roghair@uiowa.edu 
Typical rodent models have induced neonatal macrosomia through maternal overnutrition or the induction of maternal diabetes $[5,6]$. When high fat feeding occurs during gestation and lactation, pups develop a phenotype in adulthood similar to the metabolic syndrome [7-9]. These studies are consistent with epidemiological evidence showing that maternal obesity plus neonatal macrosomia increase the risk of developing metabolic syndrome [10]. While the maternal overnutrition model replicates a common cause of neonatal macrosomia, the independent long-term effects of neonatal macrosomia remained clouded by unknown programming effects of maternal obesity and obesity-induced diabetes mellitus. To define the effects of isolated neonatal macrosomia, we sought to compare macrosomic mice to isogenic controls co-fostered by healthy dams receiving standard laboratory feed.

While beginning our investigation into the long-term consequences of natural perinatal growth variation, we demonstrated that spontaneous neonatal growth restriction programs the development of metabolic syndrome in isogenic mice $[11,12]$. As in other programming models, marked sexual dimorphism was noted, with neonatal growth restriction eliciting hypertension in adult male mice and glucose intolerance in adult female mice [12]. Notably, the C57Bl6 strain of mice used in those studies is known to carry a genetic predisposition to metabolic syndrome with relative hypertension seen in female mice and glucose intolerance seen in male mice [13-16]. We hypothesized that naturally occurring neonatal macrosomia would exacerbate this sexually dimorphic predisposition to aspects of the metabolic syndrome, and the introduction of a high fat diet in adulthood would further accentuate the phenotypes of macrosomic mice.

\section{Methods}

\section{Animal Model}

The investigation was approved by the University of Iowa Animal Care and Use Committee and conforms to National Institutes of Health guidelines. Adult C57Bl/6J mice (Jackson Laboratory, Bar Harbor, Me., USA) were bred for 2 weeks, and then moved into individual cages. Dams delivered naturally, fostered their own pups, and were maintained on standard rodent chow (4 kcal/g, 6\% of energy as fat; 7013; Harlan Teklad, Madison, Wisc., USA) throughout pregnancy and lactation. Pups were weighed upon weaning (day 20 of life). Utilizing standard clinical criteria, macrosomia was identified by a gender-specific weight above the 90th percentile. For control mice, appropriate growth was defined by a weight within 1 standard deviation of the colony mean. For every macrosomic mouse identified (21 males and 18 females), littermate control mice were retained ( 27 males and 25 females). All study groups consisted of mice from at least 14 different litters.

\section{Baseline Studies}

At 20 weeks, glucose and insulin tolerance tests were performed following a 3-hour fast, as previously described [12]. For glucose tolerance tests, $20 \%$ dextrose was administered by intraperitoneal injection $(2 \mathrm{~g} / \mathrm{kg})$. After at least $48 \mathrm{~h}$ of recovery, insulin tolerance tests were performed by intraperitoneal injection of regular human insulin (0.75 U/kg; Humulin-R; Eli Lilly, Indianapolis, Ind., USA). Insulin levels were measured on plasma collected from fasting mice immediately prior to glucose tolerance testing, as previously described [12]. Following the endocrine tests, tail cuff systolic blood pressure (SBP) and heart rate were recorded for 5 consecutive days, as previously described [11, 12]. During the final week on the baseline diet, feed intake was recorded and an exercise wheel $(35 \mathrm{~cm}$ circumference, Thoren Caging Systems, Hazleton, Pa., USA) was placed inside each cage to evaluate voluntary activity. Exercise wheel revolutions were digitally recorded over the ensuing $72 \mathrm{~h}$.

\section{High Fat Diet}

After completing the baseline studies, 12-15 mice/group were switched to a hypercaloric, high fat diet $(5 \mathrm{kcal} / \mathrm{g}, 45 \%$ of energy as fat; D12451; Research Diets, New Brunswick, N.J., USA). The caloric composition of the diet included $45 \%$ fat (39\% lard and 6\% soybean oil), $35 \%$ carbohydrates ( $18 \%$ sucrose, $10 \%$ maltodextrin, and $7 \%$ corn starch), and $20 \%$ protein $(19.7 \%$ casein and $0.3 \%$ L-cystine). Twenty weeks later, glucose and insulin tolerance tests were repeated. The mice were then weighed and anesthetized for organ harvest.

\section{Data Analysis}

All values are presented as mean \pm SEM. Statistical comparisons were performed by 2-tailed t test or ANOVA with Bonferroni post hoc testing when appropriate. A Shapiro-Wilk test was employed as a test of normality. Levene's test was used to verify homogeneity of variances.

\section{Results}

\section{Establishment of the Model}

Median litter size was 7 pups with an interquartile range of 6-9 pups. Weanling weight was inversely correlated with litter size (fig. 1a; $\mathrm{R}^{2}=0.9$ ). Neonatal mouse weights were normally distributed (fig. $1 \mathrm{~b} ; \mathrm{W}=0.99, \mathrm{p}>$ $0.05)$. Female mice weighed significantly less than male mice on day 20 (female $8.1 \pm 0.1$, male $8.4 \pm 0.1 \mathrm{~g}$; $\mathrm{p}<$ $0.05)$. Based on the initial 178 male mice, macrosomia (weight above the 90th percentile) was defined by weight above 9.80 g on day 20 (fig. 1b). Based on the initial 156 female mice, the corresponding 90th percentile weight was $9.40 \mathrm{~g}$ (fig. 1b). By definition, macrosomic pups weighed more than control pups at weaning (fig. 1c). 


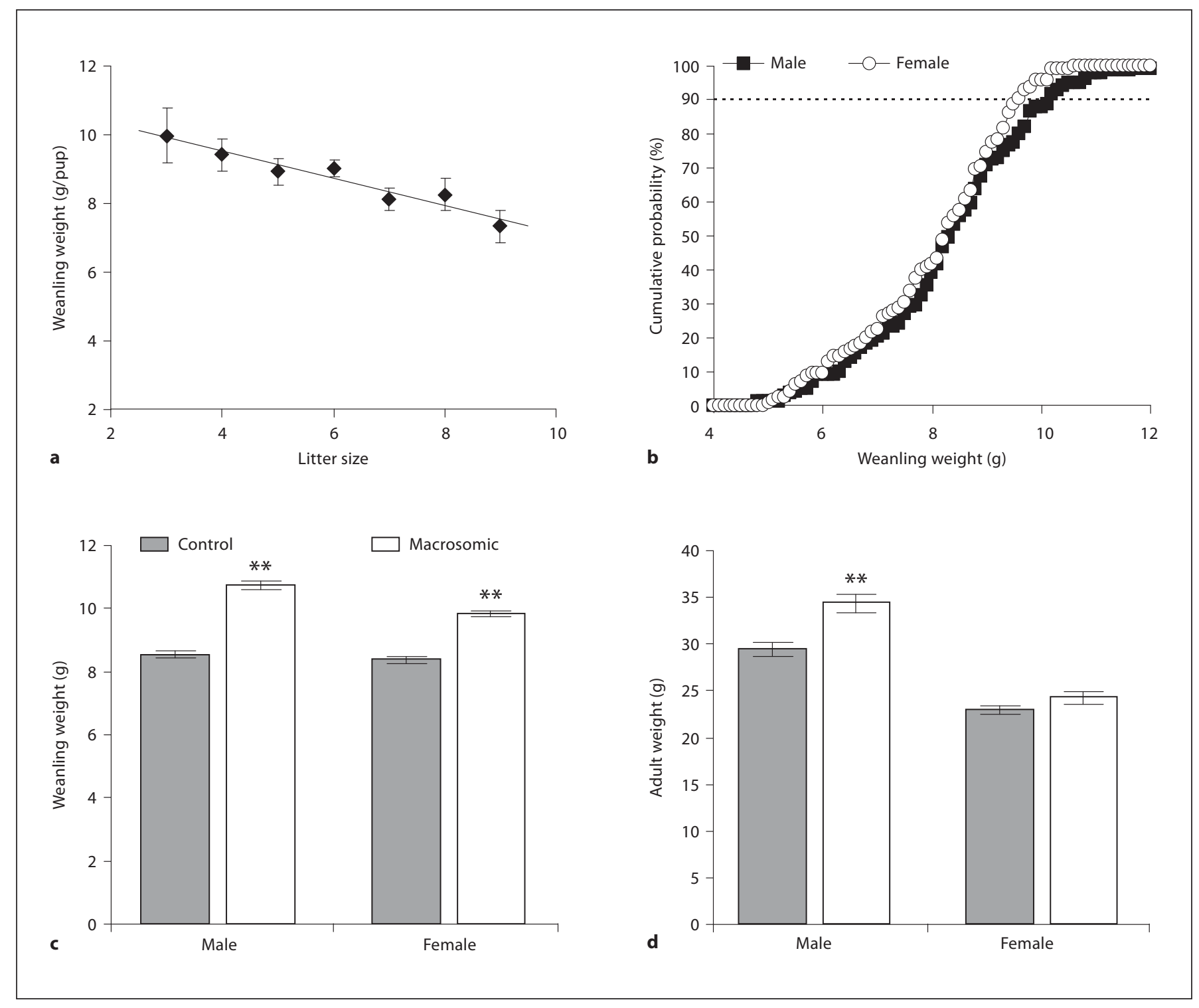

Fig. 1. In isogenic C57BL/6 mice, weanling weight was inversely proportional to litter size (a; 57 litters, $\left.\mathrm{R}^{2}=0.9\right)$. Male and female mice had normally distributed weanling weights (b; 334 mice, $\mathrm{W}=0.99$ ). Neonatal macrosomia was defined by a weight greater than the 90th percentile on postnatal day 20. Weanling (c) and adult weights (d) were measured on postnatal day 20 and at 20 weeks, respectively. ${ }^{* *} \mathrm{p}<0.01$ versus control by t test.

\section{Phenotypes on Standard Chow}

At 20 weeks, macrosomic males weighed significantly more than the controls, while female macrosomic mice showed no significant difference in adult weight versus controls (fig. 1d). While neither macrosomic males nor macrosomic females had altered caloric intake compared to the controls (macrosomic male $509 \pm 33$, control male $552 \pm 31$, macrosomic female $701 \pm 18$, control female $670 \pm 10 \mathrm{kcal} / \mathrm{kg} /$ day), macrosomic males had signifi- cantly reduced voluntary activity (macrosomic male 1.4 \pm 0.2 , control male $3.1 \pm 0.4$, macrosomic female $5.7 \pm$ 0.8 , control female $6.0 \pm 0.6 \mathrm{~km} /$ day). Macrosomic females had elevated SBP (macrosomic $115 \pm 3$ versus control $108 \pm 1 \mathrm{~mm} \mathrm{Hg}, \mathrm{p}<0.05)$ with decreased heart rate (macrosomic $616 \pm 15$ vs. control $667 \pm 11$ bpm, $\mathrm{p}<$ 0.01 ), whereas macrosomic males had no significant alterations in heart rate (macrosomic $591 \pm 25$ vs. control $588 \pm 11 \mathrm{bpm}$ ) or blood pressure (macrosomic $111 \pm 3$ 


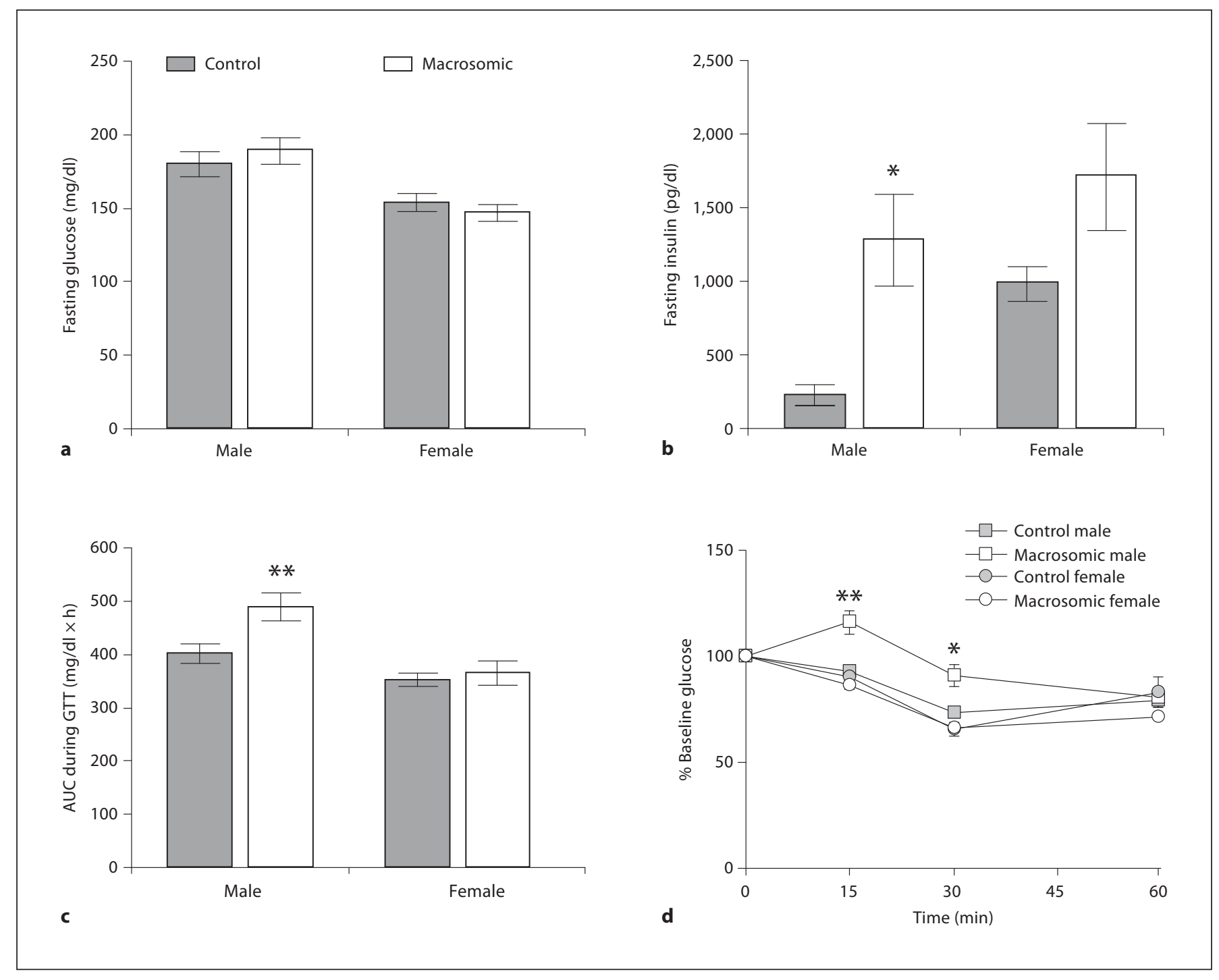

Fig. 2. Fasting glucose (a) and insulin (b) levels were measured among control and macrosomic mice prior to glucose tolerance test $(\mathbf{c})$ and insulin tolerance test $(\mathbf{d}) .{ }^{*} \mathrm{p}<0.05,{ }^{* *} \mathrm{p}<0.01$ versus control by ANOVA.

vs. control $109 \pm 2 \mathrm{~mm} \mathrm{Hg}$ ). Although there were no alterations in fasting glucose levels in male or female mice (fig. 2a), macrosomic males had elevated fasting insulin levels (fig. $2 b ; p<0.05$ ) with equal variance confirmed by Levene's test. Compared to control males, macrosomic males also had impaired glucose tolerance (fig. 2c) and reduced insulin sensitivity (fig. $2 \mathrm{~d}$ ). In comparison to females, males overall had decreased activity $(\mathrm{p}<0.001)$, increased fasting glucose (fig. $2 \mathrm{a} ; \mathrm{p}<0.001$ ), impaired glucose tolerance (fig. $2 c ; p<0.001$ ) and reduced insulin sensitivity (fig. $2 \mathrm{~d} ; \mathrm{p}<0.01$ ).

Neonatal Macrosomia Programs Adult Physiology

\section{Phenotypes on High Fat Chow}

While on a high fat diet, female mice gained more weight than male mice $(\mathrm{p}<0.01)$, but neonatal macrosomia did not alter this relationship (fig. 3a). Compared to phenotypes on standard chow, male $(\mathrm{F}=277, \mathrm{p}<0.001)$ and female mice $(\mathrm{F}=245, \mathrm{p}<0.001)$ had an overall impairment in glucose tolerance that was independent of their weanling weight classification (fig. 2c compared with fig. 3c). Only the males had insulin resistance $(\mathrm{F}=$ $21, p<0.001)$ independent of their weanling weight classification (fig. 3d). Compared to control females, macrosomic females had no significant alteration in fasting glu-

Neonatology 2010;98:238-244 


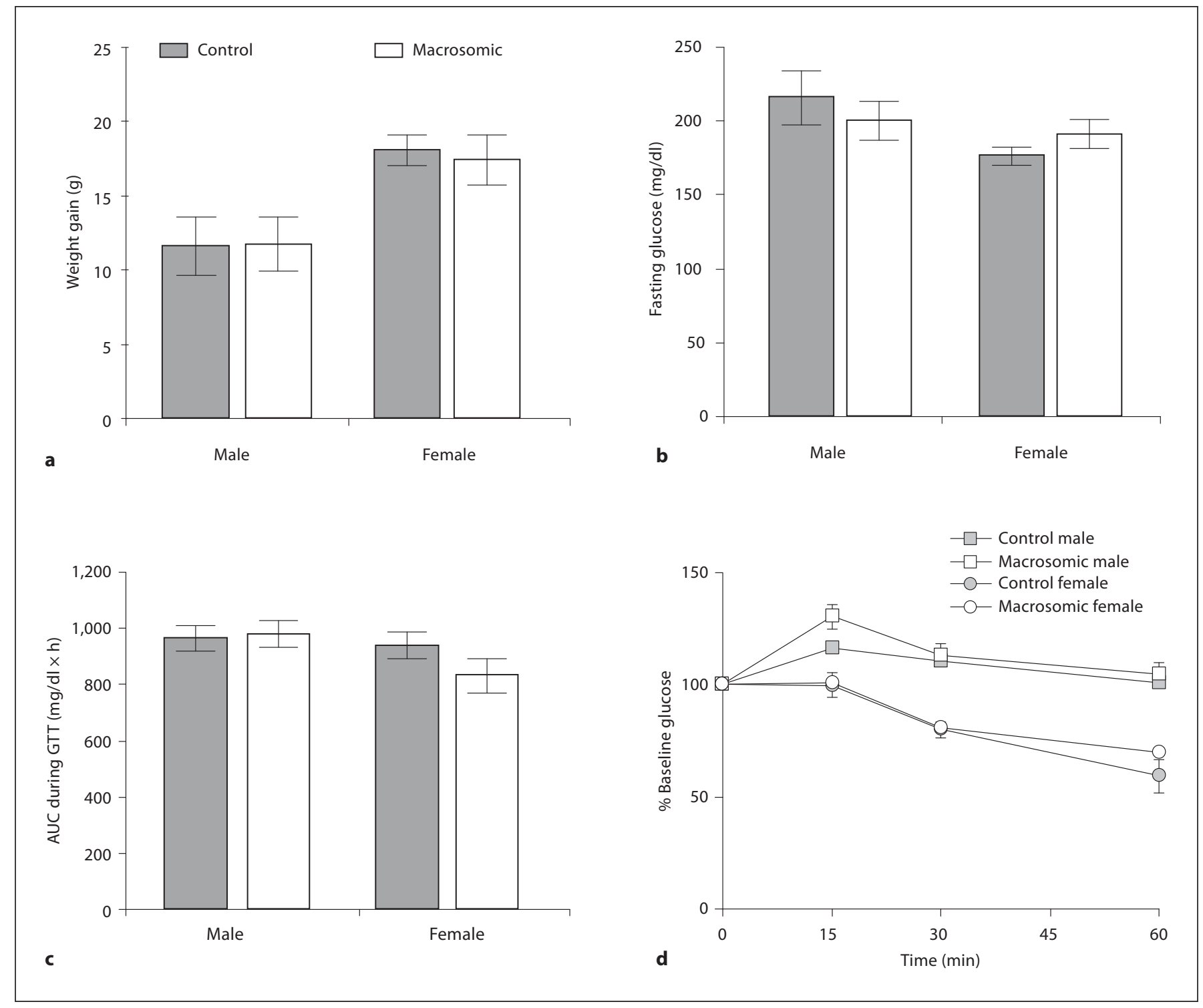

Fig. 3. After 20 weeks of high fat diet administration, weight gain (a) and fasting glucose levels (b) were measured among the control and macrosomic mice prior to the glucose tolerance test (c) and insulin tolerance test (d).

cose (fig. 3b), glucose tolerance (fig. 3c), or insulin sensitivity (fig. 3d).

At the completion of the high fat intervention, macrosomic male mice had significantly increased body weight compared to the controls ( $\mathrm{p}<0.01$; table 1). Macrosomic females, but not males, had a significant reduction in adult brain weight versus controls (table 1). Compared to male mice, female mice were significantly lighter and had a significant increase in the relative weight of the brain, heart and white adipose tissue, yet a significant decrease in relative liver weight (table 1).

\section{Discussion}

Our unique model allows us to conclude that neonatal macrosomia is an independent risk factor for components of the adult metabolic syndrome. We demonstrate that neonatal macrosomia accentuates the sexually dimorphic predisposition of C57Bl6 male mice towards glucose intolerance and C57Bl6 female mice towards hypertension. We further demonstrate that the long-term effects of neonatal macrosomia are not accentuated, but are rather masked by the introduction of a high fat diet in adulthood. 
Table 1. Growth parameters for control and macrosomic adult mice following administration of a hypercaloric high fat diet

\begin{tabular}{lcclc}
\hline & $\begin{array}{l}\text { Male } \\
\text { control }\end{array}$ & $\begin{array}{l}\text { Male } \\
\text { macrosomic }\end{array}$ & $\begin{array}{l}\text { Female } \\
\text { control }\end{array}$ & $\begin{array}{l}\text { Female } \\
\text { macrosomic }\end{array}$ \\
\hline Mice, $\mathrm{n}$ & 14 & 12 & 15 & 12 \\
Weight, $\mathrm{g}^{\dagger \dagger}$ & $44.6 \pm 0.9$ & $47.7 \pm 1.1^{* *}$ & $42.3 \pm 1.2$ & $44.1 \pm 1.6$ \\
Brain, $\mathrm{mg} / \mathrm{g}^{\dagger}$ & $13.2 \pm 0.7$ & $12.2 \pm 0.6$ & $18.0 \pm 0.4$ & $16.0 \pm 0.6^{*}$ \\
Heart, $\mathrm{mg} / \mathrm{g}^{\dagger \dagger}$ & $5.1 \pm 0.2$ & $5.0 \pm 0.4$ & $6.1 \pm 0.3$ & $6.1 \pm 0.4$ \\
Liver, $\mathrm{mg} / \mathrm{g}^{\dagger \dagger}$ & $61 \pm 4$ & $69 \pm 6$ & $52 \pm 2$ & $52 \pm 3$ \\
Kidneys, $\mathrm{mg} / \mathrm{g}$ & $14.1 \pm 0.9$ & $13.2 \pm 1.0$ & $14.8 \pm 0.5$ & $15.2 \pm 1.1$ \\
White adipose, $\mathrm{mg} / \mathrm{g}^{\dagger \dagger}$ & $101 \pm 17$ & $95 \pm 5$ & $213 \pm 14$ & $207 \pm 25$ \\
Brown adipose, $\mathrm{mg} / \mathrm{g}$ & $7.5 \pm 0.6$ & $8.5 \pm 0.7$ & $8.7 \pm 1.0$ & $7.9 \pm 1.3$ \\
\hline
\end{tabular}

${ }^{*} \mathrm{p}<0.05$ or $^{* *} \mathrm{p}<0.01$ versus control by ANOVA; ${ }^{\dagger} \mathrm{p}<0.05$ or $^{\dagger \dagger} \mathrm{p}<0.01$ for male versus female by ANOVA.
This is the first study to identify long-term physiologic alterations attributable to natural neonatal macrosomia in a colony of isogenic mice raised under standard laboratory conditions. It is clear that divergent patterns of neonatal growth and nutrition exert independent effects of adult health [17]. In contrast to the protective endocrine effects of neonatal growth restriction [11], excessive childhood growth increases the risk of metabolic syndrome in adulthood [18]. Given the importance of both birth weight and childhood weight gain in the establishment of adult susceptibility [1-3, 18], we used weanling weight rather than birth weight as a marker of increased disease risk. Of note, Fok et al. [19] recently validated a number of neonatal anthropometric indices that can be monitored to tailor neonatal nutrition towards optimal growth and development.

Accentuating the sexual dimorphism towards higher blood pressures seen in C57Bl6 females [14], neonatal macrosomia led to sex-specific programming of cardiovascular outcomes in female mice. Sex-specific programming of hypertension has been seen in many models of developmental programming [20,21]. With studies showing a reversal of these gender differences following gonadectomy and a recapitulation of the phenotypes with hormonal replacement [22-24], it is possible that sex hormone levels play an important role in the elaboration of programmed adult phenotypes.

Intriguingly, macrosomic females had both increased blood pressures and reduced brain weight. Neonatal brain growth and development is known to display strong sexual dimorphism [25]. We have previously demonstrated that postnatal growth restriction also leads to a decline in absolute brain weight that is likewise associated with tail cuff hypertension [11, 12]. Neurobehavioral testing and radiotelemetric blood pressure recordings during both rest and psychologic stress would help clarify the role of altered neonatal neurodevelopment in the programming of adult blood pressure.

Alternatively, the relative reduction in macrosomic female brain weight may reflect a disproportionately increased body weight. This was not the case for heart weight ratios. We speculate that heart weight remained proportional to body weight in macrosomic mice given the presence of significant hyperinsulinism (primarily in males) and hypertension (primarily in females). Longitudinal tissue weights would help address whether the altered adult tissue weights are a direct result of asymmetric neonatal growth patterns or an indirect consequence of neonatal macrosomia-induced adult disease.

In contrast to macrosomic females, macrosomic males had sex-specific programming of endocrine outcomes that was associated with a decreased level of voluntary exercise. We speculate that these phenotypes (inactivity, insulin resistance, hyperinsulinism and glucose intolerance) are linked, but further studies are necessary to define the primary alteration. Since early exercise has been found to prevent insulin resistance and diabetes, the long-term effects of early exercise intervention in susceptible populations should be investigated [26]. Obesityprone male mice with neonatal macrosomia are one population that may be amenable to early intervention.

Surprisingly, the introduction of a high fat diet in adulthood did not accentuate the phenotypes of macrosomic mice. It is possible that the lack of interaction between neonatal macrosomia and the administration of a high fat diet was masked by the development of significant glucose intolerance in even the control mice. The presence of a ceiling effect could be studied by assessing 
the effects of shorter courses of high fat diet administration, for example, limiting high fat diet administration to 4 rather than 20 weeks.

\section{Perspectives and Significance}

This unique isogenic mouse model demonstrates that the neonatal environment elicits long-term physiologic alterations. The pathways responsible for these altera- tions have yet to be elucidated, and it is possible that the effects of neonatal macrosomia are most pronounced in animals, such as the C57BL6 strain of mice, that have a genetic predisposition towards obesity, diabetes and hypertension. Further investigations into the links between the early environment and later health may facilitate the prevention of adult metabolic syndrome in obesity-prone individuals.

\section{References}

$\checkmark 1$ McCance D, Pettitt D, Hanson R, Jacobsson L, Knowler W, Bennett P: Birth weight and non-insulin dependent diabetes: thrifty genotype, thrifty phenotype, or surviving baby genotype? BMJ 1994;308:942-945.

-2 Parsons TJ, Power C, Logan S, Summerbell CD: Childhood predictors of adult obesity: a systematic review. Int J Obes Relat Metab Disord 1999;23:S1-S107.

-3 Tian JY, Cheng Q, Song XM, Li G, Jiang GX, Gu YY, Luo M: Birth weight and risk of type 2 diabetes, abdominal obesity and hypertension among Chinese adults. Eur J Endocrinol 2006;155:601-607.

-4 Wei JN, Sung FC, Li CY, Chang CH, Lin RS, Lin CC, Chiang CC, Chuang LM: Low birth weight and high birth weight infants are both at an increased risk to have type 2 diabetes among schoolchildren in Taiwan. Diabetes Care 2003;26:343-348.

$\checkmark 5$ Cottrell EC, Ozanne SE: Early life programming of obesity and metabolic disease. Physiol Behav 2008;94:17-28.

6 Khan NA: Role of lipids and fatty acids in macrosomic offspring of diabetic pregnancy. Cell Biochem Biophys 2007;48:79-88.

7 Armitage JA, Taylor PD, Poston L: Experimental models of developmental programming: consequences of exposure to an energy rich diet during development. J Physiol 2005;565:3-8.

-8 Elahi MM, Cagampang FR, Mukhtar D, Anthony FW, Ohri SK, Hanson MA: Long-term maternal high-fat feeding from weaning through pregnancy and lactation predisposes offspring to hypertension, raised lipids and fatty liver in mice. Br J Nutr 2009;102: 514-519.

-9 Srinivasan M, Katewa SD, Palaniyaappan A, Pandya JD, Patel MS: Maternal high-fat diet consumption results in fetal malprogramming predisposing to the onset of metabolic syndrome-like phenotype in adulthood. Am J Physiol Endocrinol Metab 2006;291:E792E799.
10 Boney CM, Verma A, Tucker R, Vohr BR: Metabolic syndrome in childhood: association with birth weight, maternal obesity, and gestational diabetes mellitus. Pediatrics 2005;115:e290-e296.

11 Hermann GM, Miller RL, Erkonen GE, Dallas LM, Hsu E, Zhu V, Roghair RD: Neonatal catch up growth increases diabetes susceptibility but improves behavioral and cardiovascular outcomes of low birth weight male mice. Pediatr Res 2009;66:53-58.

12 Roghair RD, Aldape G: Naturally occurring perinatal growth restriction in mice programs cardiovascular and endocrine function in a sex- and strain-dependent manner. Pediatr Res 2007;62:399-404.

13 Collins S, Martin TL, Surwit RS, Robidoux J: Genetic vulnerability to diet-induced obesity in C57BL/6J mouse: physiological and molecular characteristics. Physiol Behav 2004; 81:243-248.

14 Deschepper CF, Olson JL, Otis M, GalloPayet N: Characterization of blood pressure and morphological traits in cardiovascularrelated organs in 13 different inbred mouse strains. J Appl Physiol 2004;97:369-376.

15 Gallou-Kabani C, Vigé A, Gross MS, Rabès JP, Boileau C, Larue-Achagiotis C, Tomé D, Jais JP, Junien C: C57BL/6J and A/J mice fed a high-fat diet delineate components of metabolic syndrome. Obesity 2007;15:19962005.

16 Toye AA, Lippiat JD, Proks P, Shimomura K, Bentley L, Hugill A, Mijat V, Goldsworthy M, Moir L, Haynes A, Quarterman J, Freeman HC, Ashcroft FM, Cox RD: A genetic and physiological study of impaired glucose homeostasis control in C57BL/6J mice. Diabetologia 2005;48:675-686.

17 Hay WW Jr: Strategies for feeding the preterm infant. Neonatology 2008;94:245-254.
18 Beardsall K, Ong KK, Murphy N, Ahmed ML, Zhao JH, Peeters MW, Dunger DB: Heritability of childhood weight gain from birth and risk markers for adult metabolic disease in prepubertal twins. J Clin Endocrinol Metab 2009;94:3708-3713.

19 Fok TF, Hon KL, Ng PC, Wong E, So HK, Lau J, Chow CB, Lee WH; Hong Kong Neonatal Measurements Working Group: Use of anthropometric indices to reveal nutritional status: normative data from 10,226 Chinese neonates. Neonatology 2009;95:23-32.

20 Grigore D, Ojeda NB, Alexander BT: Sex differences in the fetal programming of hypertension. Gend Med 2008;5(suppl A):S121S132.

21 Khan I, Dekou V, Hanson M, Poston L, Taylor P: Predictive adaptive responses to maternal high-fat diet prevent endothelial dysfunction but not hypertension in adult rat offspring. Circulation 2004;110:1097-1102.

22 Hong J, Stubbins RE, Smith RR, Harvey AE, Núñez NP: Differential susceptibility to obesity between male, female and ovariectomized female mice. Nutr J 2009;8:11.

-23 Ojeda NB, Grigore D, Robertson EB, Alexander BT: Estrogen protects against increased blood pressure in postpubertal female growth restricted offspring. Hypertension 2007;50:679-685.

24 Riant E, Waget A, Cogo H, Arnal JF, Burcelin $\mathrm{R}$, Gourdy P: Estrogens protect against highfat diet-induced insulin resistance and glucose intolerance in mice. Endocrinology 2009;150:2109-2117.

25 Carrer HF, Cambiasso MJ: Sexual differentiation of the brain: genes, estrogen, and neurotrophic factors. Cell Mol Neurobiol 2002; 22:479-500.

26 Patterson CM, Dunn-Meynell AA, Levin BE: Three weeks of early-onset exercise prolongs obesity resistance in DIO rats after exercise cessation. Am J Physiol Regul Integr Comp Physiol 2008;294:R290-R301. 